\title{
Changes In Higher Education: How To Address The Learning Needs Of The Latino Population
}

Armin Harbrecht, Graduate Student at The Graduate College of Union College Presha E. Neidermeyer, (E-mail: neidermp@union.edu),The Graduate College of Union Tracy L. Tuten, Virginia Commonwealth University

\begin{abstract}
Institutions of higher learning in the United States are facing challenges associated with changing demographics. Latino students are making up an increasing portion of the incoming student body than previously. The unique cultural characteristics of Latino students will require adaptations to the teaching techniques typically used in American business schools. The unique environment in business schools provides opportunities and challenges for Latino students and their instructors. We use Hofstede's cultural classifications in order to map the characteristics of Latino students and suggest six business teaching suggestions designed to increase the learning outcomes for the Latino students.
\end{abstract}

\section{INTRODUCTION}

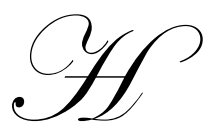

igher education faces many different enrolments trends in the future. These enrolment trends, however, are distinctly different from than those that have come in the past. While educators are predicting an overall decrease in the number of students graduating from secondary institutions, certain ethnic groups in the US population will actually experience an increase in graduation rates. One of these groups represented by increasing numbers is Hispanic students.

These students, however have historically been underrepresented in both 4 year and post graduate work (Jaschik 2005). Various reasons have been cited for this under -representation (including lack of familial background as a result of being first-generation college educated; lack of financial means; unfamiliarity with the educational systems; and less rigorous secondary institutions $\sim$ for a more complete list see Brown, Santiago, Lopez 2003.

In the coming years, those in higher education will face increased competition for acquiring and potential difficulty in maintaining a student base. Educators will need to become aware of alternate teaching techniques to help their differentiated student base be successful during their educational careers and subsequently during their working career. This study will focus on what educators can do to assist their Hispanic students in finishing their studies and being successful in their careers.

\section{Trends In Higher Education}

There are various institutions involved in higher education separated into private and public institutions. Within the marketplace there are over 640 institutions offering bachelors degrees; 640 offering masters' degrees and 260 offering doctoral degrees (NCES/PEDS). These institutions fall into a wide array of generally recognized categories put forward by the Carnegie Institution (www.carnegiefoundation.org). This forms a relatively large market with over fifteen million customers in 1998 (Postsecondary Education Opportunity August 2001). In this paper, we will concentrate on schools of business that compete in an environment somewhat smaller but in an increasingly competitive market for students. The projected college enrolments in the coming years can be represented by the following chart. 


\section{Projected College Enrollments}

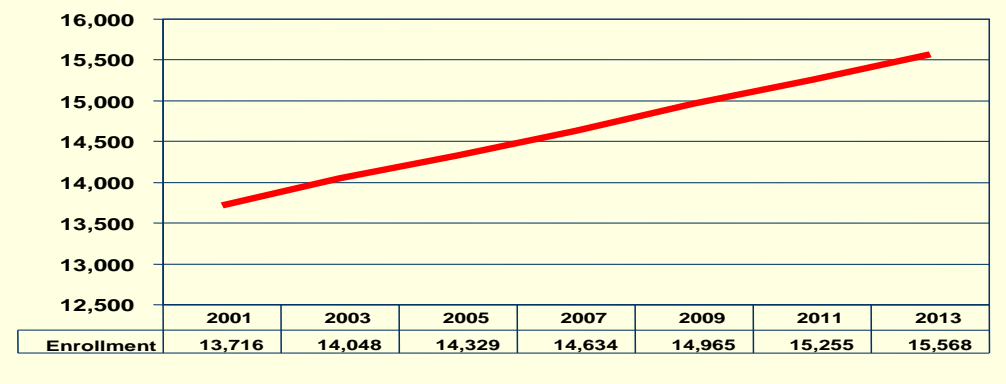

Source: NCES, The Condition of Education 2004

One of the key factors in representing the projected college enrolments during these years is the change in high school graduation rates by region. Of particular interest is the increase in graduation rates in the Southwest, South and Western regions of the United States.

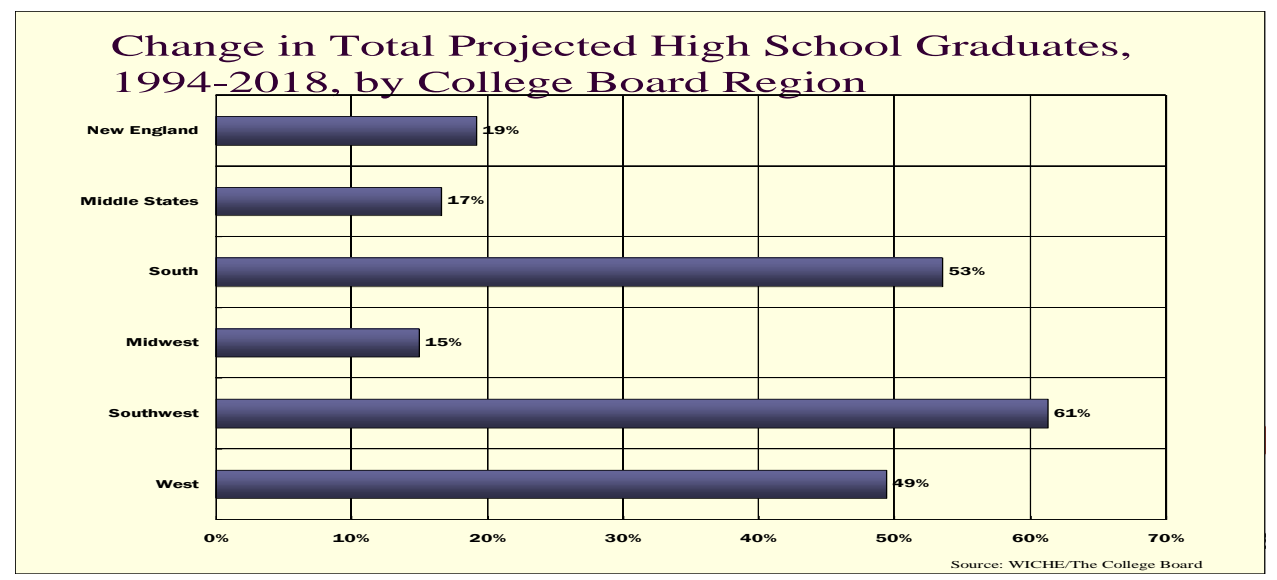

Looking at the trends once again and predicting the sea change that will be seen in higher education within the coming years, there is an increase of over $10 \%$ of high school graduation rates in only three states: California, Colorado and New Jersey. These same states will see an increase in high school graduates of higher than $10 \%$. Secondarily, the states of Louisiana, Florida, Georgia, North Carolina, Maryland, Pennsylvania, New York, Connecticut, and Rhode Island will experience an increase in graduation rates of between 5 and $10 \%$ while the rest of the country either will lose the percentage of high school graduates or will experience significantly smaller growth patterns. 


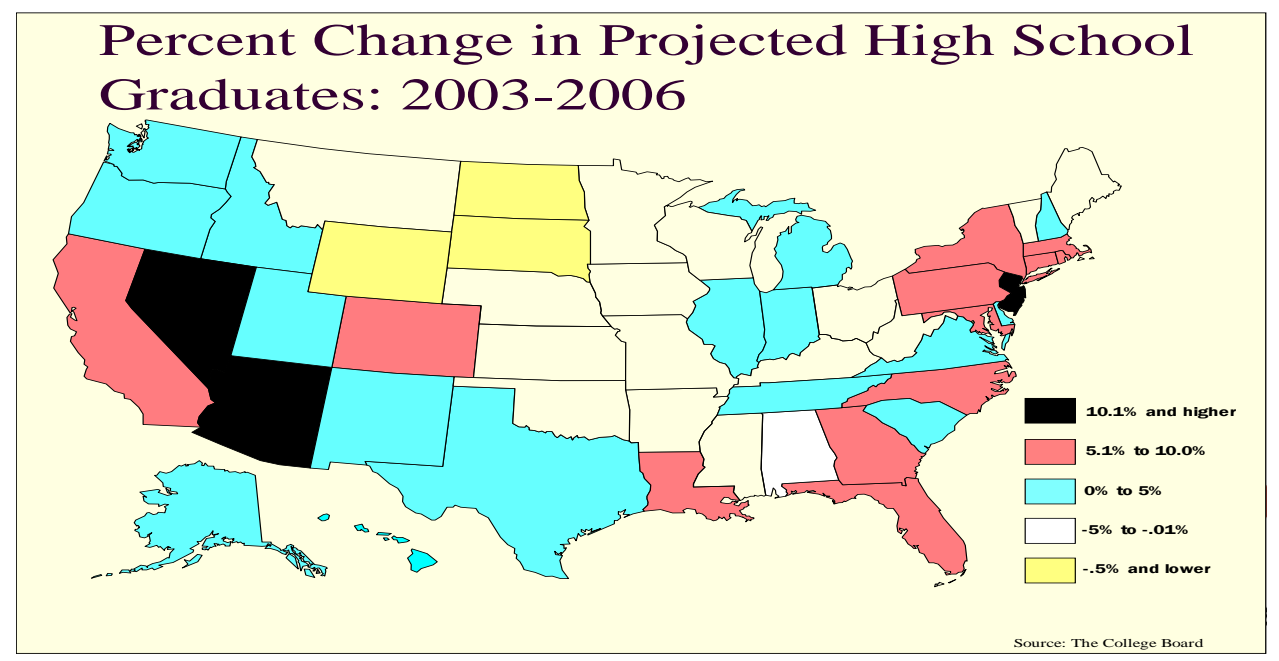

In terms of overall enrolments there will be an increasing trend in the 18-24 year old age bracket.

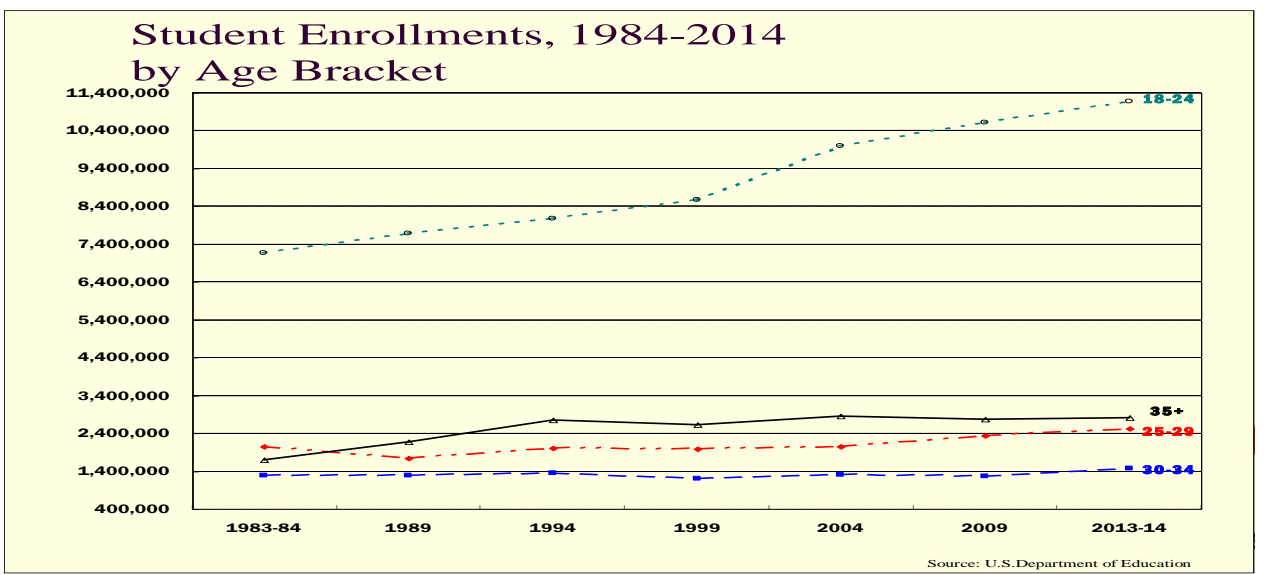

While normally the graduation rates of the population rise and fall at consistent rates with all demographic classes of individuals being equally affected, presently the country is undergoing a different trend. High school graduation rates of those individuals self-identifying as whites, blacks and Asians will decrease in the coming years while the graduation rates of Hispanic students will increase incrementally, providing a unique set of challenges for higher education providers to recruit, retain and educate the new population of inbound college students. We will now discuss some notable findings in cross-cultural research and bring these findings to bear in the suggestions for increasing the retention of Latino students through alternate teaching methods. 


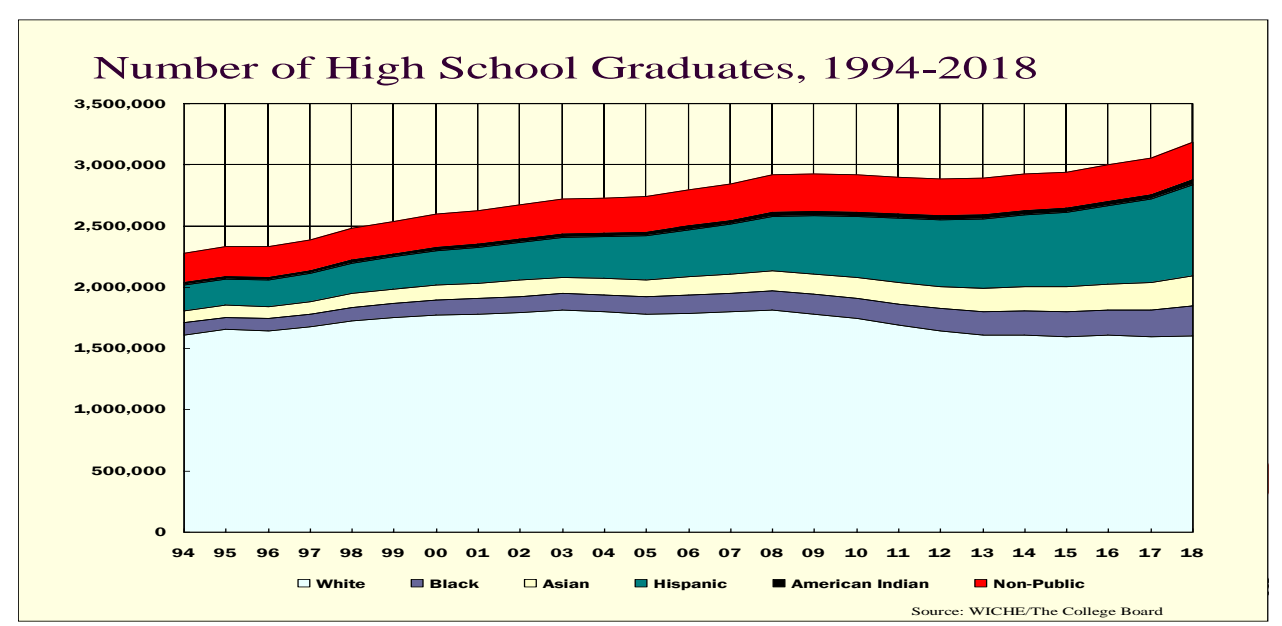

\section{Cross Cultural Research}

Hofstede is a frequently cited author who has made substantial contributions in the field of cross cultural research. His research studies identify five constructs of difference between individuals coming from different cultures. These constructs are power distance, masculinity / femininity, uncertainty avoidance, individualism and Confucian dynamism.

\section{Power Distance}

Power distance is defined as the acceptance of a higher power in decision making. Higher power distance countries readily accept authority, have parents that place high value on children's obedience, have negative association about power and wealth and prefer a decision-making style polarized between autocratic-paternalistic and majority rule (1980, p. 119). Relative scores of power distance can be seen in Table 1. The majority of countries whose culture would be defined as Hispanic have relatively higher power distance scores representing the ability and desire to have different levels of power and a greater relative happiness for following directions.

\section{Uncertainty Avoidance}

Hofstede defines uncertainty avoidance as the way in which a culture will attempt to cope with uncertainty about the future through the use of technology, law and religion. Individuals from Hispanic cultures tend to have a relatively higher uncertainty avoidance score. This suggests that they will require relatively more assurance to reduce uncertainty about the future. In teaching Latino students, these students will have a greater fear of failure and be lower-risk taking than students from higher uncertainty avoidance

\section{Individualism}

This construct captures the relative importance of the way people live together in a society. In high individualistic societies there is an importance of time for a personal life and an emotional independence from the company. In lower individualistic societies there is importance assigned to the training and physical provisions of the company and an emotional dependence on the company. Students from high individualistic countries value enjoyment in life and find it socially acceptable to claim that they will pursue their own ends without minding others. Students from relatively low individualistic countries stated that is was less socially acceptable to claim they wished to pursue their own ends without minding others and felt that duty in life was more important than enjoyment. 


\section{Masculinity/Femininity}

These two ends of the construct are differentiated by higher masculinity countries showing a higher affinity to valuation of higher earnings and personal advancement as compared to higher value assigned to interpersonal aspects, rendering service and the physical environment being valued more in more feminine countries. Two countries have relatively high masculinity scores Mexico and Venezuela with the other countries having relatively lower masculinity (or more feminine characteristics). For business, a slightly more masculine approach is generally favoured in this country.

\section{Confucian Dynamism}

This construct measure how things change over time. Since there the data is not complete with regard to Hispanic countries, we will not include this construct as a measure in the current study.

\section{Business Education}

Successful education at U.S. Business Schools prepares students for the needs of the business environment. It has to entail methods and aims that are appreciated by students and employers. Therefore, business schools emphasize their ability to help students to "achieve success in wide range of sectors, industry and functions" (http://www.hbs.edu/mba/hbsadvantage/). Methods, such as case studies and group projects should train the students to become good team players. Another focus lies on developing leaders who are motivated to succeed in the business world. MBA graduates are deemed to be "highly ambitious knowledge worker" (Sandweiss \& Lewin, 2000). A MBA will be an experience that is "intense, rigorous, and demands independent thinking" (http://chicagogsb.edu/fulltime/academics/index.aspx). Additionally, many business schools focus on training successful entrepreneurs who influence the future. As a result of a successful business education students should have been trained in leadership, communication, interpersonal skills (Rapert, Smith, Velliquette, Garretson 2004). The methods of modern business education are developed to suit these aims. However, the methods and structure of business schools today are fairly similar to those of the 1950s (Friga, Bettis, Sullivan 2003). Thus, these institutions have to change their teaching methods when they want to reach the increasing number of Latino students.

\section{Six Top Suggestions for Teaching Latino Students}

1. Incorporate team work into the daily lives of students

a. Use alternate teaching techniques such as team projects, group class presentation, and learning

b. Latino students value and place an emphasis on teamwork, thus this should be used as a method for increasing student retention and mastery of the subject matter.

2. Educate students on the value of team work while working with the importance of independent thinking. Begin with a slow and gradual integration of team work into the day to day class schedule.

a. Independent thinking is often frowned upon in high power distance countries whereas conformity with a group is valued more highly. Use the group work as a mechanism for fostering thinking and smaller groups to help foster the ideas that novel ideas are acceptable to bring forward.

b. Encourage risk-taking in answering of questions in class.

3. Change the method for assignment of projects and assignments.

a. Begin by offering much instruction with assignments as close supervision is positively evaluated by subordinates. Incorporate ideas of self sufficiency and slowly begin to offer less in terms of detailed instructions to the student encouraging critical thinking.

4. Use cross-cultural cases to facilitate learning about other cultures in an attempt to foster the desire (or reduce fear of) living abroad and working for an individual from a foreign country.)

5. Augment business education with specific seminars in topics such as:

a. the reduction of job stress and relaxation techniques,

b. the importance of both hard and soft management skills for a successful business career ; and

c. Cultural training. 
6. Use cases and other literature and group discussion to show how individual increases in wealth can help and hurt a society. Suggest alternate methods (as opposed to merely individual wealth maximization) for making a contribution to society and give example of these to help empower Hispanic students.

\section{CONCLUSIONS}

The increasing Latino demographic will have implications for higher education overall and business education in particular over the coming years. Of particular importance will be the emphasis on group work in order to engender better retention and satisfaction with the courses taught. For students to be successful in their chosen fields, certain other culturally acceptable characteristics will need either to be augmented or reduced to succeed in higher education and again in business. It will be up to the educators and students successfully working together in order to bring these lessons to bear in the coming years as the demographics in the classrooms change.

\section{LIMITATIONS}

The current research is theoretical and does not use survey or other techniques to capture opinions about teaching pedagogies in institutions of higher learning. Future research should survey Latino students and their comfort and satisfaction with various types of teaching techniques. Experimental designs could also be instituted to document different learning conditions and their outcomes with this segment of the population.

Table One: Hofstede Constructs

\begin{tabular}{|c|c|c|c|c|c|}
\hline Country & PDI & UAI & $\mathbf{M} / \mathbf{F}$ & Ind & CF \\
\hline Argentina & 49 & 74 & 50 & 46 & $\mathrm{nl}$ \\
\hline Brazil & 69 & 74 & 44 & 38 & 65 \\
\hline Chile & 63 & 66 & 26 & 23 & $\mathrm{nl}$ \\
\hline Columbia & 67 & 77 & 56 & 13 & $\mathrm{nl}$ \\
\hline Costa Rica & 35 & 86 & 21 & 15 & 46 \\
\hline Ecuador & 78 & 67 & 63 & 8 & $\mathrm{nl}$ \\
\hline Guatemala & 95 & 101 & 37 & 6 & $\mathrm{nl}$ \\
\hline Mexico & 81 & 86 & 64 & 30 & $\mathrm{nl}$ \\
\hline Peru & 64 & 91 & 32 & 16 & $\mathrm{nl}$ \\
\hline Philippines & 94 & 45 & 58 & 32 & 32 \\
\hline Salvador & 66 & 94 & 40 & 19 & $\mathrm{nl}$ \\
\hline Spain & 57 & 89 & 35 & 51 & 32 \\
\hline Uruguay & 61 & 100 & 38 & 36 & $\mathrm{nl}$ \\
\hline Venezuela & 91 & 78 & 70 & 12 & $\mathrm{nl}$ \\
\hline
\end{tabular}

Where: PDI = Power Distance, UAI = Uncertainty Avoidance Index, M/F = Masculinity/ Femininity, IND = Individualism, CD $=$ Confucian Dynamism, and $\mathrm{nl}=$ not listed.

\section{SELECTED REFERENCES}

1. http://www.nces.ed.gov/

2. Brown, S. E., Santiago, D., and Lopez, E. (2003). Latinos in higher education: Today and tomorrow. Change, 35(2).

3. http://chicagogsb.edu/fulltime/academics/index.aspx

4. $\quad$ College Board 2005 College Bound Seniors Report, available at http://www.collegeboard.com/press/article/0, $46851,00 . \mathrm{html}$.

5. $\quad$ Friga, P.N., Bettis, R.A., Sullivan, R.S. (2003). Changes in Graduate Management Education and New Business School Strategies for the 21st Century. Academy of Management Learning \& Education. Sep 2003, 2 (3), 233-249.

6. http://www.hbs.edu/mba/hbsadvantage/ 
7. Hofstede, G. 1980. Culture's Consequences. Sage: Thousand Oaks, CA.

8. Hofstede, G. 2001. Culture's Consequences: $2^{\text {nd }}$ edition. Sage: Thousand Oaks, CA.

9. Jaschik, S. 2005. Demographic Challenges. Inside Higher Ed. Retrieved from http://www.insidehighered.com/news/2005/10/31/collegeboard

10. http://mitsloan.mit.edu/mba/

11. Rapert, M.I.,Smith, S., Velliquette, A., and Garretson, J.A. (2004). The Meaning of Quality: Expectations of Students in Pursuit of an MBA .Journal of Education for Business. Sep/Oct 2004. 80 (1), 17-25.

12. Sandweiss, D., Lewin, D. (2000). Interviews with part-time MBAs point the way for retaining executive track managers. Employment Relations Today, 27(1), 35-45. 
NOTES 